\title{
Éléments azotés de la colonne d'eau et de l'interface eau-sédiment du bassin de Marennes-Oléron: influence des cultures d'hûtres
}

\author{
Michelle Feuillet-Girard (1), Maurice Héral (2), Jean-Marc Sornin (t) \\ Jean-Marc Deslous-Paoli ${ }^{(2)}$, Jean-Michel Robert "s, \\ Françoise Mornet ${ }^{(1)}$ et Daniel Razft \\ (1) CREMA-L'HOUMEAU (CNRS-IFREMER), Case 5, I 7 I 37 -Nieul-sur-Mer (France) \\ (2) IFREMER, B.P. I 33 , I 7390 La Tremblade (France: \\ (3) Laboratoire de Biologie Marine, Université de Nantes, B.P. I044, $44^{\prime \prime 37}$ Nanles Cedex (France;
}

Reçu le 21 décombre 1987 , accepté le 28 noverubrc 1989

Nitrogenous compounds in the water column and at the sediment-water interface in the estuarine bay of Marennes-Oléron : influence of oyster farming.

Feuillet-Girard M., M. Héral, J.-M. Sornin, J.-M. Deslous-Paoli, J -M. Robert, F. Mornet, D. P.azet, Aquat. Living Resour., 1988, 1, 251-265.

\section{Abstract}

The respective influences of the sediment and of oyster (Crassostrea gigas) farming on the accumulotion and the recycling of different forms of organic and inorganic nitrogen are described. Fluxes of dissolved inorganic and organic forms of nitrogen were studied between the water column, the water overlying the sediment and the pore waters, while for particulate forms the fluxes were studied between suspended material, the "biodeposits" (faeces and pseudofaeces of Crassostrea) and the sediment. The flux of inorganic nitrogen amounts to $10.510^{6} \mathrm{~g} \cdot \mathrm{m}^{-2} \cdot \mathrm{yr}^{-1}$, while that of organic nitrogen is half this figure. The particulate flux is $15 \cdot 10^{6} \mathrm{~g} \cdot \mathrm{m}^{-2} \cdot \mathrm{yr}^{-1}$. On the other hand, the phytoplanktonic nitrogen accounts for only $6 \%$ of the total particulate nitrogen. This confirms the detrital origin of organic matter in this ecosystem. In the oyster cultivation areas the nitroger: accumulation is $94 \mathrm{~g} \cdot \mathrm{m}^{-2} \cdot \mathrm{yr}^{-1}$, while in the control zones it amounts to only $15 \mathrm{~g} \cdot \mathrm{m}^{-2} \cdot \mathrm{yr}^{-1}$. The dissolved mineral nitrogen flux from the sediment is higher under oyster culture $\left(23 \mathrm{~g} \cdot \mathrm{m}^{-2} \cdot \mathrm{yr}^{-1}\right)$ than in the control zones $\left(15 \mathrm{~g} \cdot \mathrm{m}^{-2} \cdot \mathrm{yr}^{-1}\right)$. Thus, oyster cultivation induces an additional fixation of nitrogen amounting to $71 \mathrm{~g} \cdot \mathrm{m}^{-2} \cdot \mathrm{yr}^{-1}$. Two seasonal processes characterise this ecosystem: a higl winter level of nitrates in the water column and their absorption into the sediment, accompanied by a high production of biodeposits; a spring and autumnal release of amnonia from the sediment in the presence of a high level of dissolved organic nitrogen in the water column.

Keywords : Nitrogen, Crassostrea gigas, interface, adsorption, pore water, sediment, Marennes-Oléroł.

Résumé

L'influence respective du sédiment et des populations d'huîtres cultivées (Crassostrea gigas) sur l'accumulation et le recyclage des différentes formes de l'azote organique et minéral sont précisées. Les flux d'azote minéral et organique des formes dissoutes de la colonne d'eau, des eaux interstitielles et des eaux susjacentes sont étudiés, ainsi que ceux des formes particulaires représentés par les matières en suspension, les biodépôts et le sédiment. Le flux annuel de la colonne d'eau d'azote minéral est de $10,5 \cdot 10^{6} \mathrm{~g} \cdot \mathrm{m}^{-2}$, celui de l'azote organique n'atteint que la moitié. Le flux d'azote particulaire est égal à $15 \cdot 10^{6} \mathrm{~g} \cdot \mathrm{m}^{-2} \cdot \mathrm{an}^{-1}$. Par contre l'azote phytoplanctonique ne représente que $6 \%$ de l'azote particulaire total. Ceci souligne l'origine détritique de la matière organique de cet écosystème. Dans les zones de cultures, l'accumulation d'azote est de $94 \mathrm{~g} \cdot \mathrm{m}^{-2} \cdot \mathrm{an}^{-1}$, alors qu'elle n'est que de $15 \mathrm{~g} \cdot \mathrm{m}^{-2} \cdot \mathrm{an}^{-1}$ dans les zones témoins. Les flux d'azote minéral dissous en provenance du sidiment sont plus élevés sous les cultures $\left(23 \mathrm{~g} \cdot \mathrm{m}^{-2} \cdot \mathrm{an}^{-1}\right)$ que dans le sédinent témoin $\left(15 \mathrm{~g} \mathrm{~m}^{-2}\right.$. an $\left.{ }^{-1}\right)$. Une 
culture d'huîtres induit une fixation supplémentaire d'azote de $71 \mathrm{~g} \cdot \mathrm{m}^{-2} \cdot \mathrm{an}^{-1}$. Deux comportements saisonniers caractérisent cet écosystème : (i) de forts apports hivernaux de nitrates par la colonne d'eau et leur absorption au niveau du sédiment, accompagnés d'une forte production de biodépôts; (ii) un relargage printanier et automnal d'ammonium par le sédiment en présence d'azote organique abondant dans la colonne d'eau.

Mots-clés : Azote, Crassostrea gigas, interface, adsorption, eau interstitielle, sédiment, MarennesOléron.

Différents auteurs (Robert et al., $1982 a, 1982 b$; Flamion, comm. pers.) ont montré que l'azote est le premier facteur limitant du phytoplancton sur certains sites conchylicoles de la côte atlantique française (baie de Bourgneuf et bassin de Marennes-Oléron). Par ailleurs, Robert (1982) souligne l'importance des formes azotées organiques et un bilan de ces différents constituants azotés présents dans l'eau du bassin ostréicole de Marennes-Oléron a été tenté par Héral et al. en 1981; mais il ne prend pas en compte le rôle que peut avoir le sédiment dans le relâché des éléments nutritifs (Feuillet, 1971), ni l'influence des populations de mollusques sur le cycle de l'azote. L'effet du sédiment ne peut être négligé car selon Rowe et al. (1975-1977), l'ammoniaque reminéralisé à partir de la matière organique du fond, peut procurer une grande fraction de l'azote nécessaire à la photosynthèse. Le rôle des sédiments dans le cycle des éléments nutritifs augmente l'efficacité des écosystèmes côtiers, par l'apport d'éléments nutritifs assimilables par le phytoplancton et le phytobenthos. La richesse des eaux interstitielles en éléments azotés organiques et minéraux reflète les processus de dégradation que subit la matière organique (Billen, 1976; Rutgers van der Loeff, 1980). Peu d'études donnent un budget des différentes formes de l'azote et en particulier les acides aminés, l'urée, l'azote organique. De même en ce qui concerne l'influence des mollusques, Sornin et al. (1983), Lerat et al. (1985) soulignent l'effet des biodépôts de l'huître Crassostrea gigas sur la forte accumulation de matières organiques avec un apport en azote hivernal marqué, induisant des flux à l'interface eau-sédiment de l'ion ammonium (Lerat et al., 1985). L'azote ammoniacal échangeable du sédiment représente le « pool » d'ammonium actif biologiquement au sein de ce sédiment et est plus aboridant dans les zones où sont cultivées les huîtres (Sornin et al., 1983).

L'accurnulation et le recyclage de différentes formes de l'azote organique et minéral ont été considérés dans un sédiment sans culture d'une part et dans un sédiment soumis à forte biodéposition d'huîtres d'autre part. Pour déterminer si les sédiments prenaient part au cycle de l'azote, nous avons dosé différentes formes organiques et minérales de l'eau interstitielle ainsi que l'azote total, l'ammoniaque échangeable et les nitrates mobiles de la fraction solide, dans deux zones de l'écosystème : cultivée et non cultivée.
Une liaison est faite avec la colonne d'eau où l'on individualise les formes dissoutes et particulaires.

\section{MÉTHODES}

\section{Localisation des stations ( fig. 1)}

Pour le sédiment (eau interstitielle et eau susjacente), deux stations ont été choisies, éloignées de $10 \mathrm{~m}$ sur le banc de Dagnas. L'une avec des tables d'élevage d'huîtres, l'autre sans culture servant de témoin. Ces deux stations sont au même niveau bathymétrique, présentent la même caractéristique granulométrique sablo-vaseuse, et sont soumises au même champ de courant. Avec une amplitude de marée de $5 \mathrm{~m}$, le temps d'émersion des parcs situés à un coefficient de 80 est au maximum de $1 \mathrm{~h} 30$. Les expériences de biodépôts sont réalisées sur la station avec huîtres, selon les méthodes de cultures en surélevées décrites par Héral (1985). Pour la colonne d'eau, les prélèvements sont effectués à une station proche. Les caractéristiques courantologiques du secteur montrent que l'eau surnageante du banc de Dagnas est ainsi échantillonnée en moyenne $1 / 4$ d'heure après son passage sur la zone d'échantillonnage des sédiments et biodépôts.

\section{Colonne d'eau}

Les prélèvements sont réalisés, pendant 2 ans, tous les 15 jours en mortes eaux et vives eaux, en demicycle de marée de 8 heures en surface et à $50 \mathrm{~cm}$ du fond toutes les 2 heures. La station échantillonnée est centrale et son suivi journalier est représentatif des fluctuations journalières des différentes masses d'eau du centre du bassin de Marennes-Oléron (Héral et al., 1983 b).

- Substances dissoutes : après filtration sur filtre Whatman GFC et congélation, les sels minéraux nitrites et nitrates sont analysés selon la méthode de Strickland et Parsons (1972). L'ammoniaque est fixé immédiatement après le prélèvement et dosé selon le protocole de Koroleff (1970). L'azote organique dissous est analysé après photo-oxydation par une lampe à vapeur de mercure $(1200 \mathrm{~W})$ selon les recommandations de Armstrong et Tibbits (1968). Les acides aminés sont détectés par fluorescence selon la méthode de North (1975). L'urée est dosée par une adaptation 
de la réaction avec le diacétyl monoxine à l'autoanalyseur technicon (Aminot et Kerouel, 1982).

- Substances particulaires: les analyses d'azote total sont réalisées avec un doseur CHN Perkin Elmer modèle 240 selon la méthode de Kerambrun et Szekielda (1969). Les protéines particulaires sont dosées en suivant le protocole de Malara et Chara (1972).

\section{Eau susjacente}

Les prélèvements sont effectués tous les 15 jours dans les flaques d'eau restant après 15 minutes d'émersion, à marée basse, sur le sédiment témoin en leur appliquant les mêmes techniques d'analyse que pour la colonne d'eau.

\section{Sédiment}

Les prélèvements sont réalisés immédiatement après l'émersion tous les 15 jours pour le sédiment témoin et tous les 2 mois pour le sédiment situé sous les tables à huîtres sur le banc dc Dagnas (fig. 1). Les

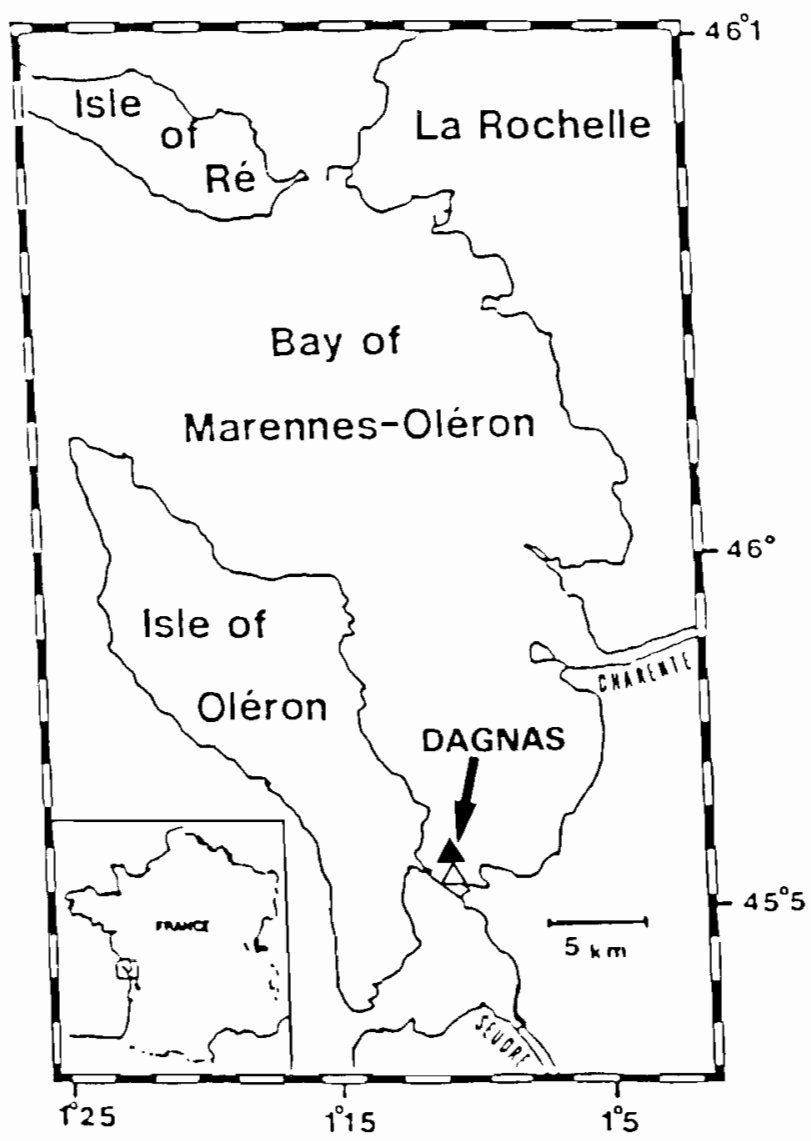

Figure 1. - Position des stations éludiées : $\triangle$ eau.

Location of the stations:

oysters and sediment; $\triangle$ water column. biodépôts sont recueillis dans un système de pièges décrit par Sornin (1981) et installé pendant 24 heures chaque mois sous des huîtres cultivées à 200 individus au mètre carré. Chaque prélèvement des sédiments et des biodépôts correspond à un suivi de la colonne d'eau. La technique de prélèvement de la vase est précisée par Sornin et al. (1983). Deux niveaux sont étudiés à $0-0,5 \mathrm{~cm}$ et $1-1,5 \mathrm{~cm}$ de profondeur.

- Eau interstitielle : l'extraction des eaux interstitielles est faite dans les 24 heures, après la récolte des échantillons, par centrifugation à 3000 tours pendant 10 minutes. Les eaux sont filtrées sur membrane Whatman GFC. Les mêmes paramètres que pour la colonne d'eau sont analysés avec des protocoles identiques.

- Sédiment et biodépôts : $\mathrm{pH}$, Eh et température ont été mesurés immédiatement après le prélèvement sur le terrain selon le protocole indiqué par Feuillet et Gouleau (1977). L'azote minéral (azote nitrique et ammoniacal échangeable) est analysé sur le sédiment humide selon une adaptation de la méthode de Drouineau et Gouny (1947). Le coefficient d'adsorption K est calculé par la relation proposée par Krom et Berner (1980).

$$
\mathrm{K}=\frac{1-\theta}{\theta} \rho_{s} \mathrm{~K}^{*}
$$

où $\theta$ est la porosité, $\rho_{s}$ est la densité du sédiment sec, ici de $2,65 \mathrm{~g} \cdot \mathrm{cm}^{-3}$. La porosité a été calculée en fonction de la teneur en eau :

$$
\theta=\text { volume d'eau/volume du sédiment humide. }
$$

$\mathrm{K}^{*}$ représente le rapport entre la concentration en ammonium échangeable en $\mu \mathrm{mol} . \mathrm{g}^{-1}$ de sédiment sec et la concentration en ammonium dissous de l'eau interstitielle en mmol. $1^{-1}$. Ce rapport permet d'évaluer l'importance de l'adsorption de l'ammonium.

Après dessication et calcul de la teneur en eau, l'azote total est dosé par la méthode de Kjeldahl, la matière organique par crémation à $450^{\circ} \mathrm{C}$ et les protéines par la méthode de Lowry et al. (1951).

\section{Estimation des flux en provenance du sédiment}

Selon les travaux de Billen (1976, 1978), les profils de concentration des eaux interstitielles permettent d'estimer le flux diffusif des différents éléments nutritifs " comme une valeur minimum de l'échange du matériel dissous " (Rutgers van der Loeff, 1980). La formule utilisée correspond à la première loi de Fick, en utilisant la formule :

$$
\mathbf{F}=-\theta . \mathrm{D}(d c / d z)
$$

$\mathrm{F}:$ flux diffusif total $\left(\mu \mathrm{mol} . \mathrm{cm}^{-2} \cdot \mathrm{s}^{-1}\right)$.

$\theta$ : porosité.

D : coefficient de diffusion apparent total. Dans les zones côtières des valeurs entre $0,3 \cdot 10^{-4}$ et $2.10^{-4} \mathrm{~cm}^{-2} \cdot \mathrm{s}^{-1}$ sont utilisées. $\mathrm{D}=1 \cdot 10^{-4} \mathrm{~cm}^{-2} \cdot \mathrm{s}^{-1}$ pour l'ensemble des calculs, valeur utilisée par Rut- 
gers van der Loeff, 1980; Liu et al., 1986).

$d c$ : gradient de concentration entre l'eau interstitielle à $0,5 \mathrm{~cm}$ et l'eau susjacente.

$d z$ : profondeur du prélèvement $(0,5 \mathrm{~cm})$, cette couche superficielle du sédiment, en contact avec l'eau susjacente, conditionne les flux à l'interface (Simon, 1988; Rutgers van der Loeff, comm. pers.).

\section{RÉSULTATS}

\section{Colonne d'eau}

\section{Substances azotées dissoutes}

- Substances minérales (fig. 3). L'ammoniaque subit des fluctuations journalières très importantes de 0,5 à $9 \mathrm{mmol} . \mathrm{m}^{-3}$ en période estivale, pouvant être du même ordre de grandeur que les variations saisonnières. A la station centrale, les teneurs oscillent entre 0,5 et $3 \mathrm{mmol} \cdot \mathrm{m}^{-3}$. Elles sont très élevées à l'été 1979 , dépassant $10 \mathrm{mmol} . \mathrm{m}^{-3}$. Les valeurs minimales se trouvent au mois de mai. Pour les nitrites, cette forme transitoire de l'azote en voie de minéralisation est présente constamment à l'état de traces. Les valeurs maximales se trouvent l'automne et l'hiver et ne dépassent pas $1,5 \mathrm{mmol} . \mathrm{m}^{-3}$, les valeurs minimales sont inférieures à $0,5 \mathrm{mmol} . \mathrm{m}^{-3}$. Les nitrites ne forment jamais plus de $4 \%$ de l'azote total. Les nitrates représentent en hiver 70 à $90 \%$ de l'azote total avec des teneurs supérieures à $50 \mathrm{mmol} . \mathrm{m}^{-3}$ ( fig. 2).

- Substances organiques (fig. 4). Les teneurs en substances organiques dissoutes azotées totales sont élevées et présentent un cycle saisonnier marqué inverse de celui des nitrates. En période hivernale, les teneurs ne dépassent pas $6 \mathrm{mmol} . \mathrm{m}^{-3}$ représentant une contribution moyenne de $5 \%$ de l'azote total. Au printemps, on note une importante production de substances organiques avec une teneur moyenne en azoie organique dissous de $25 \mathrm{mmol} . \mathrm{m}^{-3}$, teneur qui se maintient en été et augmente à nouveau à l'automne. Les variations des teneurs en urée, suivent un cycle saisonnier moins marqué que celui de l'azote organique total, avec des valeurs maximales de $5 \mathrm{~mm} 10 \mathrm{l} . \mathrm{m}^{-3}$. L'urée représente plus de $20 \%$ de l'azote total au printemps, en été et à l'automne. Les acides aminés montrent une grande variabilité quotidienne et il n'apparaît pas de cycle saisonnier net. Leurs teneurs moyennes oscillent entre 0,2 et $4,5 \mathrm{mmol} . \mathrm{m}^{-3}$ et n'expliquent que $15 \%$ de l'azote organique dissous ( fig. 2).

\section{Matières azotées particulaires (fig. 5)}

La teneur en azote organique particulaire varie avec les pics du seston avec des teneurs qui oscillent autour de $1 \mathrm{~g} \cdot \mathrm{m}^{-3}$, en vives eaux d'hiver, n'atteignant que $0,20 \mathrm{~g} \cdot \mathrm{m}^{-3}$ en mortes eaux montrant l'influence prépondérante des coefficients de marée et de l'état de
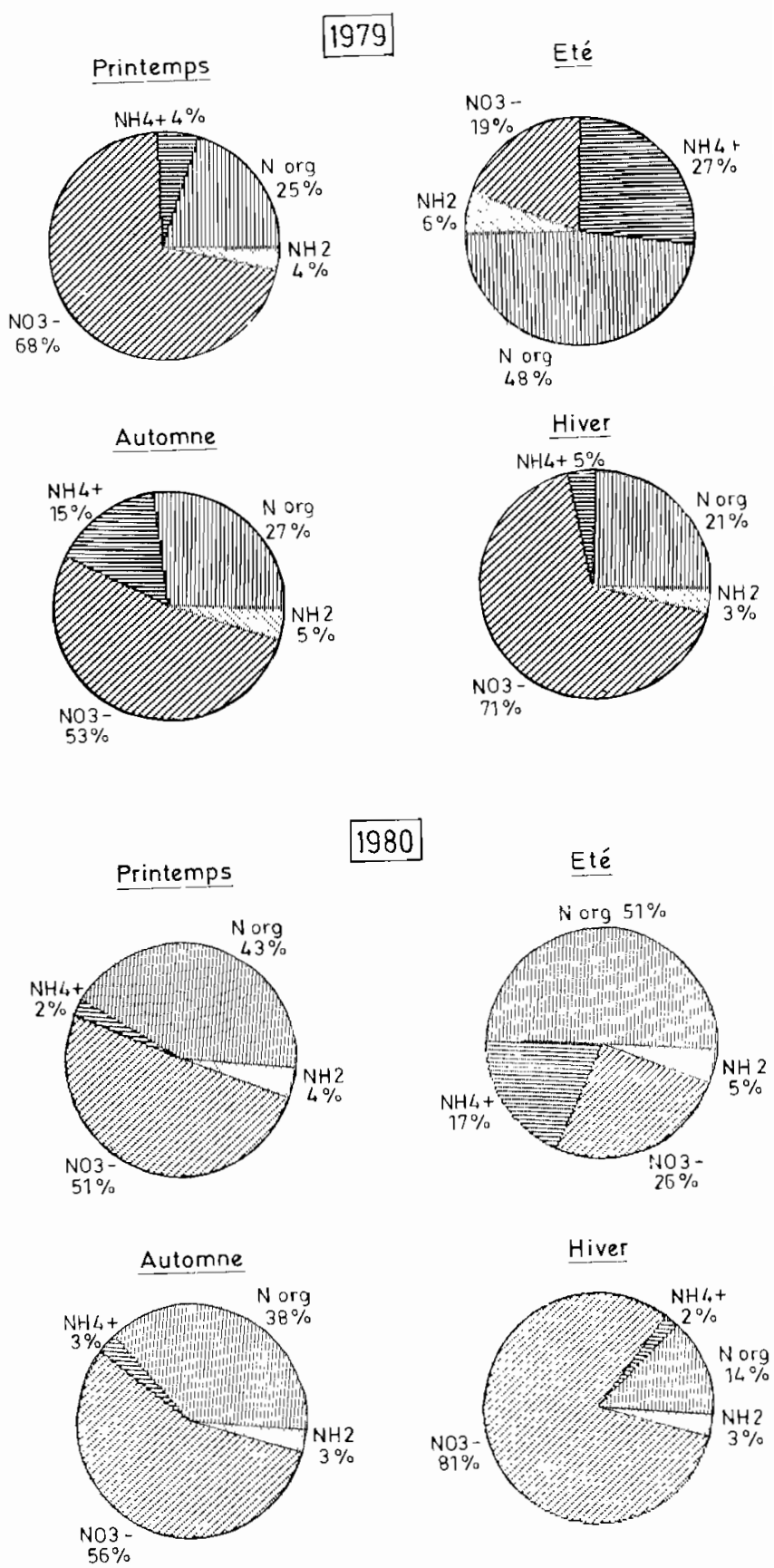

Figure 2. - Évolution saisonnière des pourcentages des principaux constituants azotés de la colonne d'eau pour l'année 1979 et l'année 1980. $\mathrm{N}$ org : azote organique total dissous; $\mathrm{NH}_{2}$ : acides aminés dissous; $\mathrm{NH}_{4}$ : ammoniaque; $\mathrm{NO}_{3}$ : nitrate.

Seasonal variations in the percentages of principal nitrogenous com. ponents of the water column in 1979 and 1980. Org $N$ : dissolved total organic nitrogen; $\mathrm{NH}_{2}$ : dissolved amines; $\mathrm{NH}_{4}$ : ammonium, $\mathrm{NO}_{3}:$ nitrate.

la mer. Au printemps, les valeurs en azote augmentent jusqu'à $0,5 \mathrm{~g} \cdot \mathrm{m}^{-3}$ en liaison avec le bloom phytoplanctonique. Les protéines sont les constituants 


\section{NITRATES}

amoles m $^{-3}$
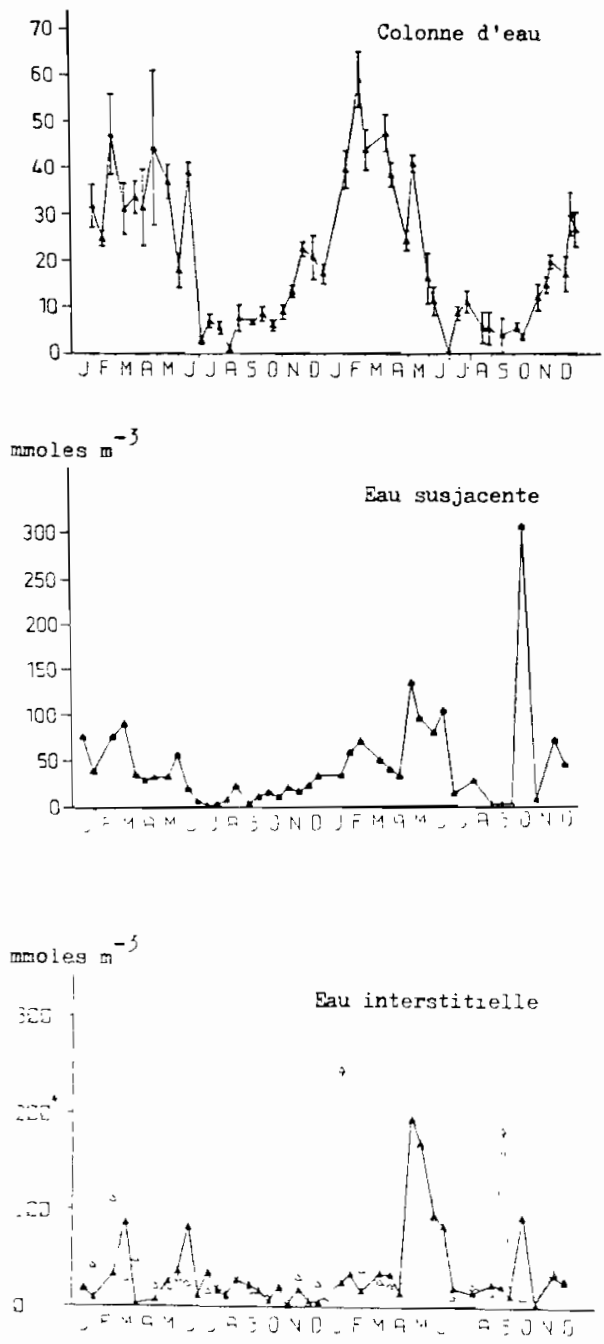

\section{AMMONIAQUE}
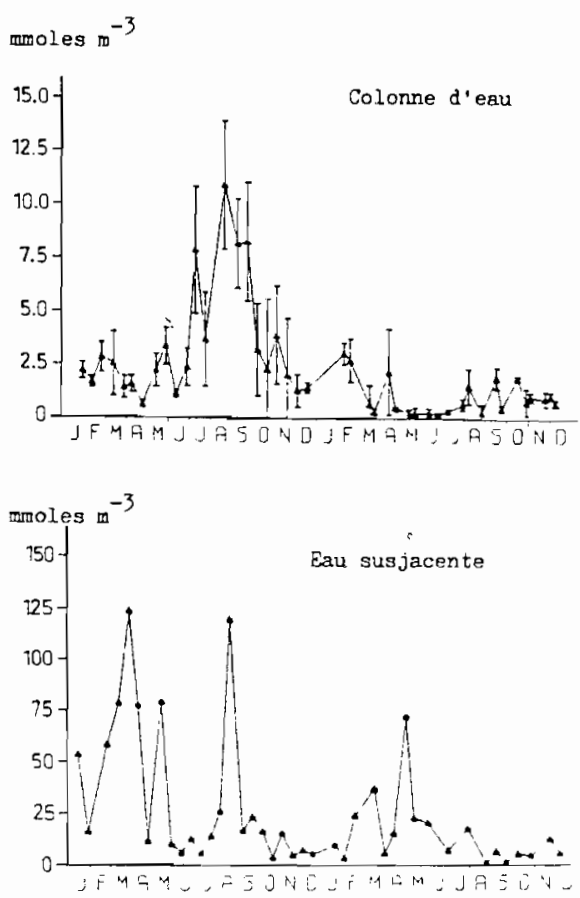

Figure 3. -- Concentrations en ammoniaque et en nitrates, $\left(\mathrm{mmol} . \mathrm{m}^{-3}\right)$ pour la colonne d'eau, eau susjacente et eau interstitielle.

$$
\begin{array}{r}
-0.5 \mathrm{~cm} \\
--1-5 \mathrm{~cm}
\end{array}
$$

Ammonium and nitrate concentrations (mmol. $\mathrm{m}^{-3}$ ) in water column, overlying water and pore water.

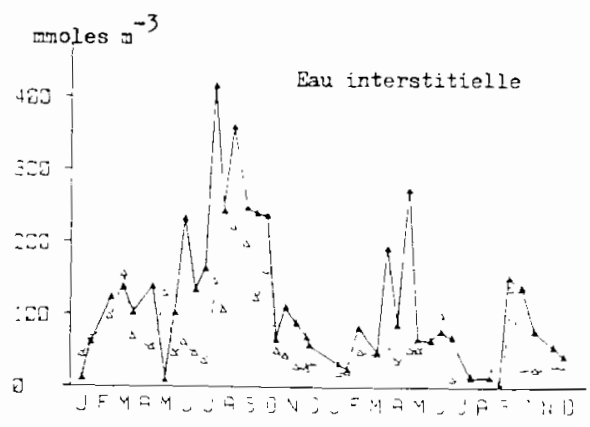

majoritaires de la matière organique en hiver $(70 \%)$ avec un maximum en hiver et en mars de $2,7 \mathrm{~g} . \mathrm{m}^{-3}$ Héral et al. (1980) montrent qu'au mois de mai, $100 \%$ des protéines particulaires sont liées au phytoplancton, tandis qu'en hiver et en été, 96 à $80 \%$ des protéines correspondent à de la matière organique détritique.

\section{Eau interstitielle et eau susjacente}

\section{Sels minéraux dissous à l'interface eau-sédiment}

Ammonium: au cours de l'année 1979, les eaux interstitielles des sédiments superficiels (niveau $0-0,5 \mathrm{~cm}$ ) sont très riches en ammonium. Les teneurs varient de 23 à $220 \mathrm{mmol} . \mathrm{m}^{-3}$. Les valeurs maxi- males se rencontrent entre juillet et septembre, les valeurs minimales sont relevées l'hiver. En 1980, les teneurs sont moins élevées que l'année précédente. Les maximums sont enregistrés en juin et septembre avec 100 et $137 \mathrm{mmol} . \mathrm{m}^{-3}$. Les minimums fin août, début septembre descendent jusqu'à $2 \mathrm{mmol} . \mathrm{m}^{-3}$. La figure 3 montre une relative constance des valeurs hivernales pour l'eau interstitielle. Le niveau inférieur est toujours plus concentré, jusqu'à trois fois plus que le niveau superficiel. La concentration dans l'eau susjacente est plus faible ou égale à celle de l'eau interstitielle du premier niveau. Cette homogénéisation n'apparaît qu'au printemps et à l'automne. L'ion ammonium dans l'eau susjacente représente jusqu'à $95 \%$ de l'ensemble de l'azote minéral. 


\section{PROTEINES}

moles $\mathrm{m}^{-3}$

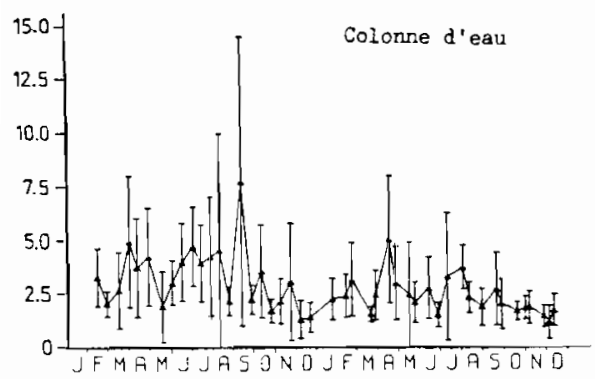

mmoles $m^{-3}$

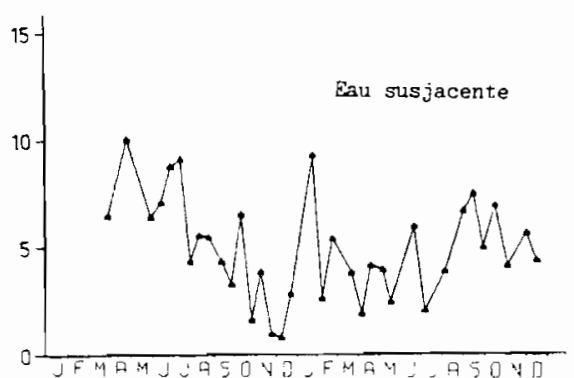

$$
\text { G. } \pi^{-3}
$$
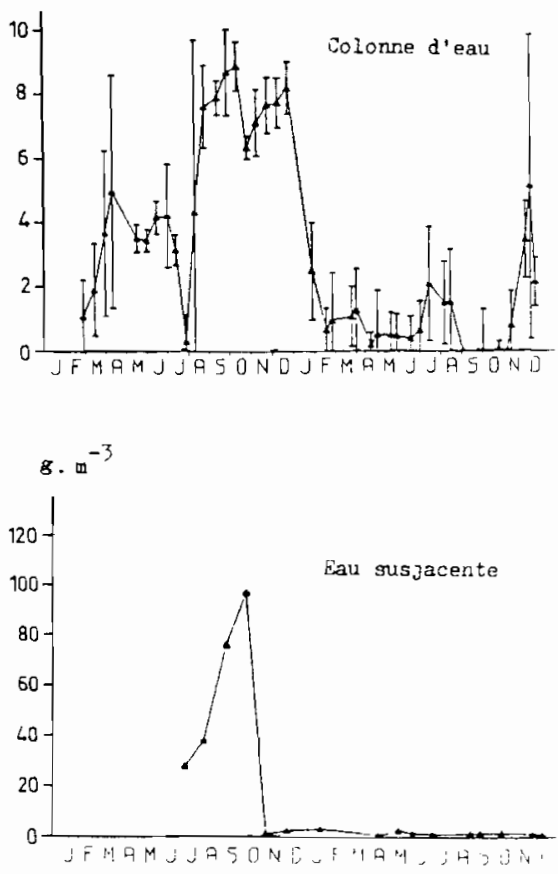

Figure 4. - Concentrations en urée et protéines, $\left(\mathrm{mmol} . \mathrm{m}^{-3}\right.$ et $\left.\mathrm{g} \cdot \mathrm{m}^{-3}\right)$ pour la colonne d'eau, eau susjacente et eau interstitielle.

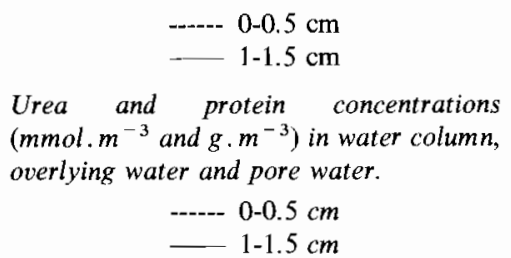

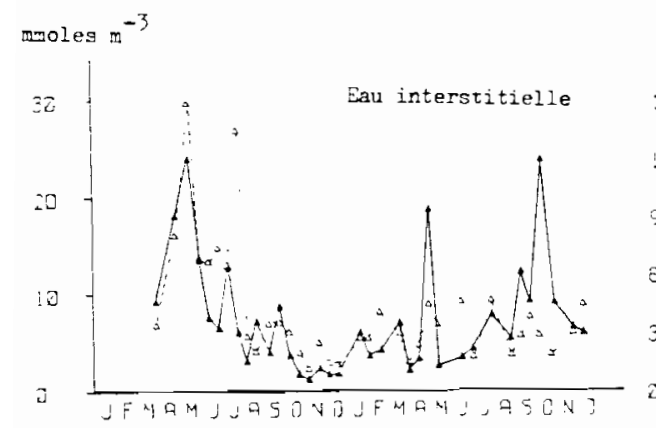

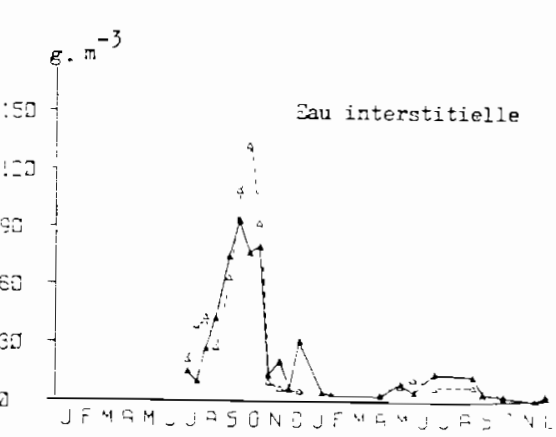

Nitrites: les nitrites sont toujours peu représentés, ils atteignent jusqu'à $8,5 \mathrm{mmol} . \mathrm{m}^{-3}$ dans l'eau susjacente au mois de juin 1980, alors qu'ils n'ont pas dépassé $5,3 \mathrm{mmol} . \mathrm{m}^{-3}$ au mois de janvier de l'année précédente. Les eaux interstitielles sont peu riches en cet élément et n'atteignent pas $4 \mathrm{mmol} . \mathrm{m}^{-3}$ en mai 1980 et $8 \mathrm{mmol} . \mathrm{m}^{-3}$ au mois de février 1979.

Nitrates : les eaux susjacentes ne dépassent jamais $100 \mathrm{mmol} . \mathrm{m}^{-3}$ au cours de l'année 1979 avec un maximum en mars $\left(91 \mathrm{mmol} . \mathrm{m}^{-3}\right)$ et un minimum l'été avec $1,8 \mathrm{mmol} . \mathrm{m}^{-3}$ avec des extrêmes de $133 \mathrm{mmol} . \mathrm{m}^{-3}$ et $1,6 \mathrm{mmol} . \mathrm{m}^{-3}$ respectivement en avril et août 1980. En 1979, les valeurs les plus fortes en nitrates de l'eau interstitielle se rencontrent comme pour la colonne d'eau en hiver avec $114 \mathrm{mmol} . \mathrm{m}^{-3}$, les plus faibles l'été avec $8,3 \mathrm{mmol} . \mathrm{m}^{-3}$. En 1980 , les valeurs hivernales sont très fortes: $245 \mathrm{mmol}^{-3}$, des teneurs élevées se retrouvent au printemps avec $196 \mathrm{mmol} . \mathrm{m}^{-3}$, puis il apparaît une nette chute estivale avec $13,3 \mathrm{mmol} . \mathrm{m}^{-3}$ ( fig. 3).

\section{Azote organique dissous à l'interface eau-sédiment}

La concentration en azote organique des eaux interstitielles peut être très élevée, jusqu'à dix fois celles des eaux susjacentes. Les teneurs en urée des eaux interstitielles sont du même ordre de grandeur que dans les eaux susjacentes. La concentration en acides aminés des eaux interstitielles est presque toujours supérieure à celle des eaux susjacentes, mise à part la période hivernale. La concentration en acides 


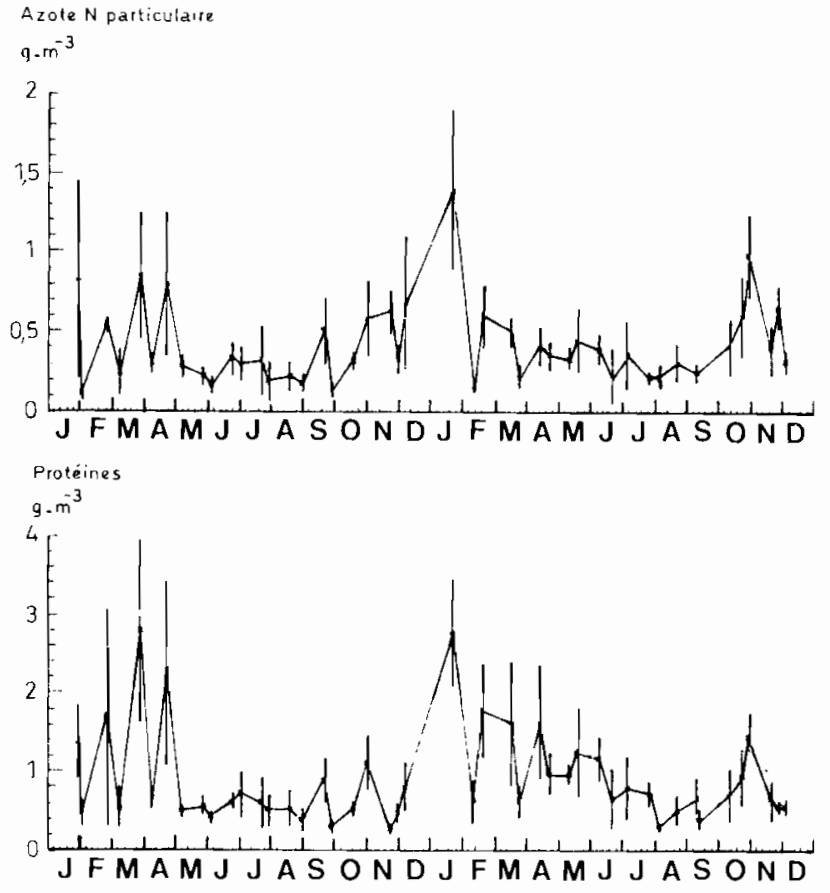

Figure 5. - Evolution des teneurs en azote particulaire ( $N$ part.) et en protéines particulaires de la colonne d'eau $\left(\mathrm{g} \cdot \mathrm{m}^{-3}\right)$.

Particulate nitrogen ( $N$ part) and particulate protein concentrations $\left(g . m^{-3}\right)$ in water column.

aminés primaires varie de $1,6 \mathrm{mmol} . \mathrm{m}^{-3}$ (glycine équivalent) à $33,5 \mathrm{mmol} . \mathrm{m}^{-3}$ dans les eaux de la pellicule superficielle du sédiment avec deux maximums en juin et novembre respectivement de 22,2 et $33,5 \mathrm{mmol} \cdot \mathrm{m}^{-3}$ (fig. 6). La concentration des amines primaires dans la couche superficielle du sédiment est

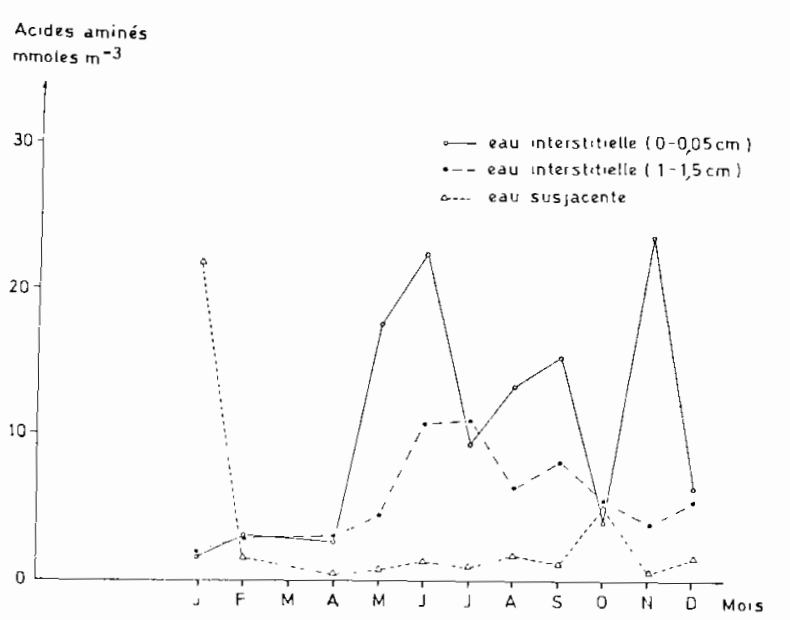

Figure 6. - Évolution des teneurs en acides aminés dans les eaux interstitielles et susjacentes de la zone témoin en $1980\left(\mathrm{mmol} . \mathrm{m}^{-3}\right)$.

Changes in amino-acid concentrations in pore waters and in the overlying water in the control zone in $1980\left(\mathrm{mmol.m} \mathrm{m}^{-3}\right)$.

vol. I, n $4-1988$

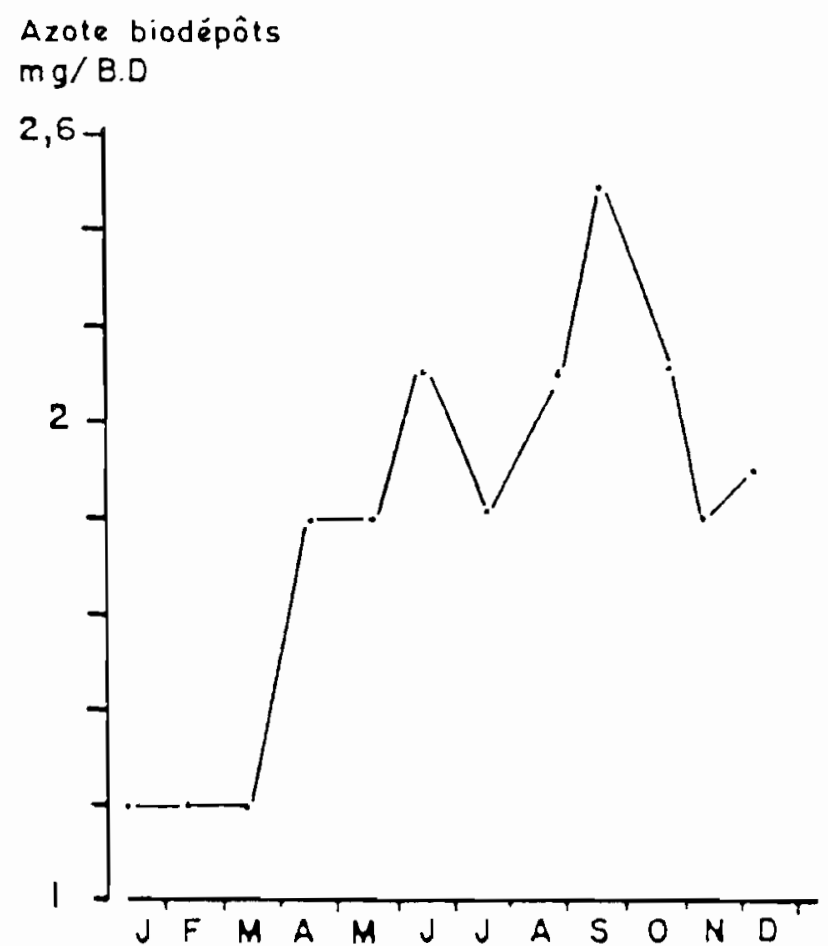

Figure 7. - Évolution saisonnière de la teneur en azote dans les biodépôts BD ( $\mathrm{mg}$ par gramme sec de biodépôt).

Seasonal changes in the nitrogen content deposits BD ( $m g$ per gram of dry biodeposit).

nettement plus élevée que la concentration de l'eau $\mathrm{du}$ fond. Les protéines dissoutes sont relativement élevées dans les eaux interstitielles et particulièrement à l'été-automne où l'on relève des concentrations de 512 à 997 g. $\mathrm{m}^{-3}$ d'équivalent albumine de bœuf.

\section{Sédiment : zone témoin}

\section{Azote organique total}

Dans la zone témoin, l'azote varie de $28 \cdot 10^{-5}$ en septembre 1979 à $66 \cdot 10^{-5}$ g par gramme de sédiment sec en décembre 1980 en passant par des maxima de $100 \cdot 10^{-5}$ à $141 \cdot 10^{-5} \mathrm{~g}$ par gramme de sédiment sec de novembre à janvier. Ceci correspond à un maximum de $2,67 \mathrm{~g} \cdot \mathrm{m}^{-2}$ et à un minimum de $0,53 \mathrm{~g} \cdot \mathrm{m}^{-2}$ qui se situe au mois de mai.

\section{Azote échangeable}

L'ammonium produit par la décomposition des composés azotés organiques peut être soit sous la forme dissoute dans les eaux interstitielles ou absorbé sur les argiles et la matière organique des sédiments. Prépondérant par rapport à l'azote nitrique, l'azote ammoniacal échangeable est abondant dans les 5 premiers millimètres du sédiment en août dépassant $16 \mathrm{~g} \cdot \mathrm{m}^{-2}$ et en mai avec $14 \mathrm{~g} \cdot \mathrm{m}^{-2}$. Les valeurs les plus faibles se situent l'hiver. 
Tableau 1. - Calculs des coefficients d'adsorption $(K)$ dans une zone d'élevage et dans une zone témoin. $\mathrm{NH}_{4}^{+}$éch. (échangeable) concentration en $\mu \mathrm{mol} . \mathrm{g}^{-1}$ de sédiment sec. $\mathrm{NH}_{4}^{+}$dis. (dissous) concentration relative au volume d'eau interstitielle (mmol. $1^{-1}$ ).

Estimates of ammonium adsorption coefficients $(K)$ in a test zone with oyster and in a control zone

\begin{tabular}{|c|c|c|c|c|c|c|c|c|c|c|}
\hline & \multicolumn{5}{|c|}{ Zone d'élevage } & \multicolumn{5}{|c|}{ Zone témoin } \\
\hline & $\begin{array}{c}\mathrm{NH}_{4}^{+} \\
\text {éch. } \\
\mu \mathrm{mol} . \mathrm{g}^{-1}\end{array}$ & $\begin{array}{c}\mathrm{NH}_{4}^{+} \\
\text {dis. } \\
\text { mmol. } \mathrm{I}^{-1}\end{array}$ & $\begin{array}{c}\mathrm{K}^{*} \\
\mathrm{ml} \cdot \mathrm{g}^{-1}\end{array}$ & $\begin{array}{c}\theta \\
\text { Porosité }\end{array}$ & $\mathrm{K}$ & $\begin{array}{c}\mathrm{NH}_{4}^{+} \\
\text {éch. } \\
\mu \text { mol. } \mathrm{g}^{-1}\end{array}$ & $\begin{array}{c}\mathrm{NH}_{4}^{+} \\
\text {dis. } \\
\text { mmol. } 1^{-1}\end{array}$ & $\begin{array}{c}\mathrm{K}^{*} \\
\mathrm{ml} \cdot \mathrm{g}^{-1}\end{array}$ & $\begin{array}{c}\theta \\
\text { Porosité }\end{array}$ & $\mathrm{K}$ \\
\hline Septembre 1979 & 0,090 & 0,196 & 0,46 & 0,45 & 1,50 & 0,011 & 0,233 & 0,05 & 0,45 & 0,15 \\
\hline Novembre & 0,108 & 0,028 & 3,87 & 0,45 & 12,53 & 0,050 & 0,029 & 1,72 & 0,45 & 5,57 \\
\hline Décembre 1979 & 0,047 & 0,071 & 0,66 & 0,45 & 2,14 & 0,052 & 0,023 & 2,26 & 0,45 & 7,32 \\
\hline Janvier 1980 & 0,067 & 0,027 & 2,52 & 0,30 & 15,58 & 0,046 & 0,018 & 2,56 & 0,31 & 15,10 \\
\hline Mars 1980 & 0,148 & 0,025 & 6,01 & 0,52 & 14,70 & 0,051 & 0,048 & 1,06 & 0,38 & 4,58 \\
\hline Mai & 0,070 & 0,684 & 1,02 & 0,39 & 4,23 & 0,050 & 1,70 & 0,45 & 0,45 & 5,50 \\
\hline Juillet 1980 & 0,513 & 0,013 & 38,00 & 0,29 & 246,00 & 0,350 & 0,084 & 4,17 & 0,55 & 9,04 \\
\hline Septembre 1980 & 0,138 & 0,170 & 0,81 & 0,29 & 1,98 & 0,050 & 0,136 & 0,37 & 0,45 & 1,20 \\
\hline
\end{tabular}

L'ammonium échangeable adsorbé est beaucoup plus abondant que l'ion ammonium dissous dans les eaux interstitielles jusqu'à 50 fois selon les périodes de l'année. Le rapport $\mathrm{K}^{*}$ varie de 0,05 à $4,17 \mathrm{ml} \cdot \mathrm{g}^{-1} \mathrm{sec}$. Les valeurs les plus faibles se trouvent à l'automne, les plus fortes en juillet. Cette variation est répétitive, au cours des deux années d'observation. Le coefficient d'adsorption lui varie de 0,15 à 15,10 (tabl. 1) dans la zone témoin.

\section{Influence de l'huître : zone d'élevage}

\section{Eau interstitielle}

Substances azotées minérales: l'eau interstitielle du sédiment des zones d'élevage est particulièrement riche en ammoniaque dissous atteignant $170 \mathrm{mmol} . \mathrm{m}^{-3}$ en septembre en surface. Ces teneurs sont plus élevées que dans la zone témoin (bien que non significativement différentes pour l'ensemble des prélèvements) en particulier au mois de mai avec respectivement 35 et $82 \mathrm{mmol} . \mathrm{m}^{-3}$ de plus pour 1979 et 1980 . La production du sédiment est intense en mai $\left(68,4 \mathrm{mmol} . \mathrm{m}^{-3}\right.$ entre $0-0,5 \mathrm{~cm}$, $212 \mathrm{mmol} . \mathrm{m}^{-3}$ entre 0,5 et $1 \mathrm{~cm}$ ). Les nitrates sont plus abondants en mars et juillet dans les zones où se trouvent les huîtres. En mai, ils ont le même comportement que l'ammonium (tabl. 2). Les formes réduites dominent généralement dans la zone de culture des huîtres: l'équilibre entre formes réduites et oxydées n'est atteint qu'au mois de mai.

Substances azotées organiques : les teneurs en protéines dissoutes, acides aminés, urée sont élevées entre le printemps et l'automne comme dans la zone témoin. La seule période où la différence est très accentuée se situe au mois de mai : les protéines atteignent alors jusqu'à $10,9 \mathrm{~g} \cdot \mathrm{m}^{-3}$ d'albumine, les acides aminés $24,7 \mathrm{mmol} . \mathrm{m}^{-3}$ et l'urée $12,3 \mathrm{mmol} . \mathrm{m}^{-3}$ en surface. Une analyse de variance indique que les substances azotées organiques et minérales varient de manière significative au cours de l'année.

\section{Sédiment}

En hiver l'azote organique total montre de fortes accumulations (tabl. 3). Ceci correspond aux apports par les biodépôts des quantités d'azote les plus importantes de janvier et février 1980 (jusqu'à $8 \mathrm{~g} \cdot \mathrm{m}^{-2}$ par jour). Ce qui s'est traduit par un enrichissement en fraction fine $(<45 \mu \mathrm{m})$ du sédiment; avec des teneurs

Tableau 2. - Substances azotées minérales et organiques des eaux interstitielles dans la zone d'élevage, H1 $(0-0,5 \mathrm{~cm}), \mathbf{H} 3(1-1,5 \mathrm{~cm})$ et dans la zone témoin, T1 $(0-0,5 \mathrm{~cm}), \mathrm{T} 3(1-1,5 \mathrm{~cm})$

Organic and inorganic nitrogenous compounds of pore water in an oysters cultivation zone, $H 1(0-0.5 \mathrm{~cm}), H 3(1-1.5 \mathrm{~cm})$, and in a control zone, $T 1(0-0.5 \mathrm{~cm}), T 3(1-1.5 \mathrm{~cm})$.

\begin{tabular}{|c|c|c|c|c|c|c|c|c|c|c|c|c|c|c|c|c|}
\hline & \multicolumn{4}{|c|}{$\mathrm{NH}_{4} \mathrm{mmol} . \mathrm{m}^{-3}$} & \multicolumn{4}{|c|}{$\mathrm{NO}_{3} \mathrm{mmol} \cdot \mathrm{m}^{-3}$} & \multicolumn{4}{|c|}{ Protéines $\mathrm{g} \cdot \mathrm{m}^{-3}$} & \multicolumn{4}{|c|}{ Urée $\mathrm{mmol} . \mathrm{m}^{-3}$} \\
\hline & H1 & $\mathrm{T} 1$ & $\mathrm{H} 3$ & $\mathrm{~T} 3$ & H1 & $\mathrm{T} 1$ & $\mathrm{H} 3$ & $\mathrm{~T} 3$ & $\mathrm{H} 1$ & $\mathrm{~T} 1$ & H3 & $\mathrm{T} 3$ & $\mathrm{H} 1$ & $\mathrm{~T} 1$ & $\mathrm{H3}$ & T3 \\
\hline 29.01 .1979 & 38 & 67 & 74 & 61 & 12 & 40 & 46 & 8 & - & - & - & - & - & - & - & - \\
\hline 14.05 .1979 & 72 & 128 & 151 & 10 & 111 & 14 & 24 & 26 & - & 27 & - & 38 & 17 & 21 & 22 & 18 \\
\hline 20.11 .1979 & 27 & 29 & 87 & 88 & 41 & 29 & 29 & 17 & - & 5 & - & 20 & 3 & 4 & 3 & 2 \\
\hline 04.12 .1979 & 71 & 23 & 67 & 69 & 29 & 4 & 16 & 6 & - & 6 & - & 6 & 3 & 3 & 2 & 1 \\
\hline 21.01 .1980 & 26 & 18 & 39 & 32 & 35 & 24 & 41 & 25 & 2 & 2 & 2 & 4 & 7 & 5 & 9 & 6 \\
\hline 17.03 .1980 & 24 & 48 & 45 & 52 & 57 & 25 & 64 & 35 & - & 3 & - & 2 & 6 & 5 & 5 & 6 \\
\hline 12.05 .1980 & 68 & 50 & 212 & 66 & 93 & 171 & 193 & 165 & 11 & 7 & 0 & 9 & 12 & 6 & 8 & 2 \\
\hline 29.07 .1980 & 13 & 84 & 39 & 97 & 48 & 19 & 94 & 15 & 3 & 6 & 13 & 14 & 7 & 9 & 6 & 7 \\
\hline 22.09 .1980 & 170 & 136 & 141 & 152 & 15 & 19 & 21 & 13 & 2 & 3 & 9 & 4 & 4 & 7 & 3 & 9 \\
\hline 24.11 .1980 & 48 & 30 & 130 & 36 & 40 & 33 & 38 & 34 & 2 & 2 & 2 & 0 & 5 & 5 & 20 & 6 \\
\hline
\end{tabular}


Tableau 3. - Distribution de l'azote organique total dans les sédiments de la zone d'élevage $(\mathrm{H} 1)$ et de la zone témoin $(\mathrm{T} 1)$.

Distribution of total organic nitrogen in sediments from an oyster cultivation zone $(H !)$ and from a control zone $(T 1)$.

\begin{tabular}{lcc}
\multicolumn{1}{c}{ Date } & \multicolumn{2}{c}{$\begin{array}{c}\text { Azote organique total } \\
\left(\mathrm{g} \cdot \mathrm{g} \mathrm{sec}^{-1}\right)\end{array}$} \\
\hline Septembre 1979 & 0,84 & 0,28 \\
Novembre 1979 & 2,51 & 1,41 \\
Décembre 1979 & 1,41 & 1,02 \\
Janvier 1980 & 7,50 & 1,02 \\
Mars 1980 & 4,60 & 0,53 \\
Mai 1980 & 2,60 & 0,40 \\
Juillet 1980 & 1,52 & 0,84 \\
Septembre 1980 & 0,80 & 0,20 \\
Décembre 1980 & 0,11 & 0,66 \\
\hline
\end{tabular}

de $66 \%$ en janvier, contre des teneurs moyennes annuelles de $30 \%$

La quantité d'amnonium échangeable la plus forte se situe en juillet. En zone d'élevage, la quantité adsorbée est le double de celle de la zone témoin en novembre et mars. Dans la zone à huîtres, les coefficients d'adsorption présentent des valeurs variables. C'est en mai, en septembre et en décembre qu'ils sont les plus faibles. Une analyse de variance montre que la présence des huîtres modifie de manière significative la quantité d'ions ammonium sur le complexe adsorbant (tabl. 4). L'effet principal est positif, mais il n'y a pas régularité, le test de Tukey montre que selon les mois, les différences peuvent être nulles. Les écarts non constants peuvent être dus à la variable sédimentaire.

\section{Biodépôts}

Les quantités globales d'azote rejetées varient en 1980 entre 1,15 en juin et $7,95 \mathrm{~g} \cdot \mathrm{m}^{-2}$ en février. De même, il apparaît une augmentation de la matière organique dans les biodépôts en mai, juin et septembre. L'enrichissement du sédiment par les biodépôts est la résultante des quantités rejetées et de leur teneur en matière organique, les plus fortes valeurs se situent à trois périodes de l'année, mars, mai et octobre (fig. 7).

\section{Estimation des flux à l'interface eau-sédiment}

Ammonium (fig. $8 \mathrm{~A}$, B et C)

Les flux calculés varient de -162 à +518 pour l'année 1979 et de $-56 \grave{a}+359 \mu \mathrm{mol} . \mathrm{m}^{-2} \cdot \mathrm{h}^{-1}$ pour l'année 1980, les flux positifs sont dans le sens sédiment-eau. Selon les années, l'importance des flux varie, mais les valeurs les plus élevées se rencontrent toujours de juillet à octobre. Dans une zone à huîtres, l'intensité des flux d'ammonium est plus forte en particulier pour la période de mai à novembre. Cependant une analyse de variance ne montre pas de différence significative entre les flux de la zone témoin et ceux de la zone cultivée.

\section{Nitrates}

Les gradients d'interface pour les nitrates confirment que l'eau fournit du nitrate au sédiment particulièrement en hiver jusqu'au début du printemps. L'été, le sédiment est généralement une source de nitrates pour la colonne d'eau. En 1979, les flux de nitrates varient de -184 à $+106 \mu \mathrm{mol} . \mathrm{m}^{-2} \cdot \mathrm{h}^{-1}$. Dans une zone témoin en 1980, les flux varient de -589 à $+422 \mu \mathrm{mol} \cdot \mathrm{m}^{-2} \cdot \mathrm{h}^{-1}$. Les flux de nitrates peuvent dépasser $400 \mu \mathrm{mol} . \mathrm{m}^{-2} \cdot \mathrm{h}^{-1}$. L'analyse de variance ne permet pas de démontrer de différence significative entre la zone témoin et la zone de culture.

\section{DISCUSSION}

\section{Phase liquide}

Les eaux interstitielles présentent dans la majorité des cas, des concentrations en azote minéral dissous, supérieures à celles que l'on peut mesurer dans les eaux susjacentes. Lorsque l'eau susjacente est plus riche en formes minérales dissoutes, ses teneurs sont voisines de celles de la couche superficielle du sédiment $(0-0,5 \mathrm{~cm})$. Les différentes formes de l'azote minéral ne contribuent pas de la même manière aux différences observées. Les nitrites ne représentent qu'une faible part de l'ensemble de l'azote inorganique $(10 \%)$. De même, dans des études précédentes, Héral et al. $(1981,1983)$ constatent que l'ion ammonium constitue généralement moins de $10 \%$ du stock total d'azote dans la colonne d'eau, sauf en été où il peut

Tableau 4. - Analyse de variance de l'ammonium échangeable dans une zone témoin et une zone cultivée (logiciel Stat ITCF). Facteur 1 : station; facteur 2 : date.

Variance analysis of exchangeable ammonium in a control zone and in a oyster cultivation.

\begin{tabular}{lccccccc}
\hline & $\begin{array}{c}\text { Somme } \\
\text { des carrés } \\
\text { des écarts }\end{array}$ & d.d.l. & $\begin{array}{c}\text { Carrés } \\
\text { moyens }\end{array}$ & Test F Probabilité & $\sigma$ & $\begin{array}{r}\text { Variance } \\
\text { expliquée }\end{array}$ \\
\hline Var. totale & 257784,98 & 15 & 17185,67 & & & & \\
Var. facteur 1 & 14762,23 & 1 & 14762,23 & 8,44 & 0,0224 & & \\
Var. facteur 2 & 230775,98 & 7 & 32968,00 & 18,84 & 0,0007 & & \\
Var. résiduelle 1 & 12246,77 & 7 & 1749,54 & & & 41,83 & $35,7 \%$ \\
\hline
\end{tabular}



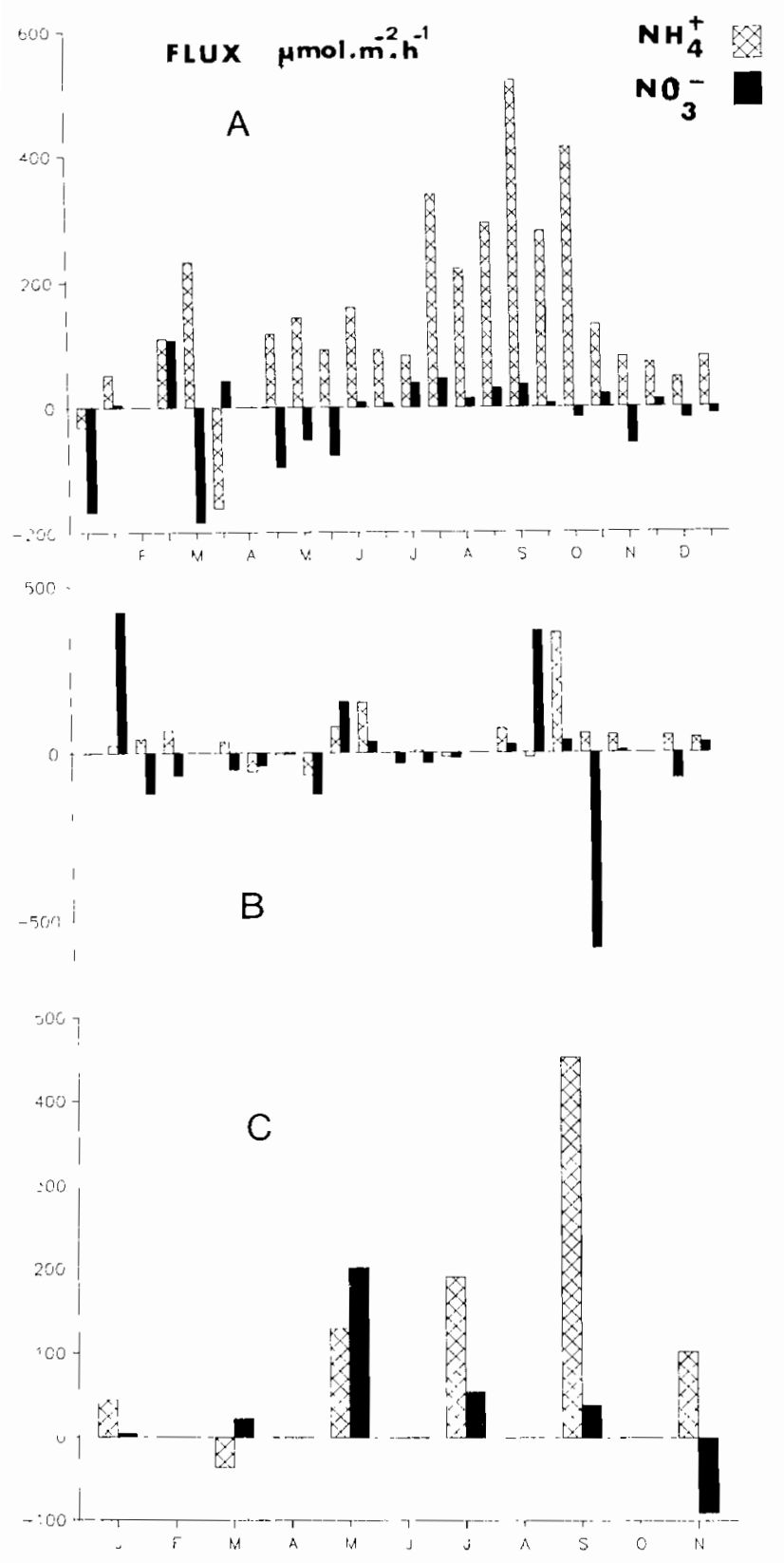

Figure 8. - Évolution des flux d'ammonium et de nitrates. A : dans une zone témoin en 1979; B : dans une zone témoin en 1980; $\mathrm{C}:$ dans une zone d'élevage d'huîtres en $1980\left(\mu \mathrm{mol} . \mathrm{m}^{-2} . \mathrm{h}\right)$.

Changes in ammonium and nitrate fluxes. $A$ : in a control zone in 1979; $B$ : in a control zone in 1980; $C$ : in a oyster cultivation zone in $1980\left(\mu \mathrm{mol} . \mathrm{m}^{-2} \cdot h\right)$

présenter jusqu'à $40 \%$ de l'azote total et être à ce moment de l'année la forme quasi unique d'azote minéral. Sa distribution présente une analogie entre la colonne d'eau et l'eau interstitielle, avec un facteur multiplicatif de 30 pour cette dernière. Cette différence de concentration indique un flux d'ammonium en direction de l'eau susjacente et particulièrement l'été.
Héral et al. (1981) proposent une production endogène du bassin autant par minéralisation de la matière organique que par excrétion des huîtres (Robert et al., $1982 b$; Vincendeau, 1987). En effet, les fortes teneurs semblent correspondre aux périodes d'excrétion active des mollusques (Héral et al., 1987).

Les flux estimés dans cette étude sont du même ordre que ceux mesurés par des incubations de carottes en laboratoire de secteurs conchylicoles bretons (Lerat et al., 1985). Les flux d'ammonium cités dans la littérature (Pomroy et al., 1983) montrent tous des variations saisonnières du même ordre de grandeur que celles qui sont calculées ici. Le sédiment est en mesure de fournir de l'azote pour la production primaire au printemps-été et à l'automne. Quant aux nitrates, les forts apports telluriques hivernaux en provenance de la Charente avec $150 \mathrm{mmol} . \mathrm{m}^{-3}$, constituent une source pour les eaux interstitielles du sédiment, par contre en été, il est mis en évidence un quasi-épuisement des nitrates $\left(0,5\right.$ à $\left.1 \mathrm{mmol} . \mathrm{m}^{-3}\right)$. Ce mécanisme a été rencontré par d'autres auteurs : Billen (1978), Rutgers van der Loeff (1981). L'été, l'épuisement des nitrates dans la colonne d'eau ne semble pas compensé par les fortes concentrations des eaux interstitielles. Le flux diffusif des nitrates du sédiment vers l'eau susjacente peut être masqué par une consommation instantanée des nitrates par le microphytobenthos, les microphytes et les macrophytes.

De tous les sels organiques azotés, ce sont les amines primaires qui dans l'eau interstitielle présentent des concentrations plus élevées que dans l'eau $\mathrm{du}$ fond. Ces valeurs pour les eaux interstitielles sont du même ordre de grandeur que celles trouvées par J $\phi$ rgensen (1979), comprises entre 15 et $56 \mathrm{mmol}^{-\mathrm{m}^{-3}}$ dans les sédiments estuariens. Les résultats donnés pour les eaux interstitielles du banc Dagnas sont similaires à ceux trouvés dans d'autres baies comme la baie Buzzards par Henrichs et Farrington ou J $\phi$ rgensen (1981) qui signalent une activité microbienne accrue. Parallèlement, Christensen et al. (1983) indiquent l'importance de l'azote aminé dissous et de son flux en direction de l'eau susjacente.

Dans les zones où sont élevées les huîtres, les flux d'ammonium sont plus importants, principalement de mars à mai, période qui correspond à un fort enrichissement du sédiment par les biodépôts.

\section{Phase solide}

La matière organique du sédiment a soit une origine autochtone provenant de la sédimentation d'organismes planctoniques ou benthiques marins, soit une origine allochtone de source continentale. Les mesures de ${ }^{13} \mathrm{C}$ semblent montrer que cette matière organique est d'origine marine et non continentale (Fontugne, comm. pers.). De la même manière, dans des études précédentes sur le même site, Héral et al. (1980) montrent qu'au mois de mai, $100 \%$ des protéines particulaires sont liées au phytoplancton, tandis qu'en hiver 
et en été 96 à $80 \%$ des protéines correspondent à de la matière détritique. Dans les zones de cultures d'huîtres, les quantités d'azote organique total sont du même ordre de grandeur que celles trouvées au Japon dans des zones d'élevage d'huîtres par Kusuki (1981). Les valeurs de la zone témoin se rapprochent de celles trouvées par Blackburn et Henricksen (1983) dans l'ouest Kattegat. La présence des cultures d'huîtres peut accroitre la production d'azote organique total jusqu'à huit fois plus que dans la zone témoin. Ces augmentations se font sentir en période hivernale (Feuillet, 1980), période où la quantité quotidienne d'azote rejetée peut atteindre $8 \mathrm{~g} \cdot \mathrm{m}^{-2}$ (Sornin et al., 1983; Deslous-Paoli et al., 1987).

\section{Relations entre phase liquide et phase solide du sédiment}

Les faibles valeurs d'ammoniaque échangeable mesurées en hiver semblent correspondre au blocage de la minéralisation. Le pic d'azote ammoniacal de septembre pourrait être lié à la minéralisation du matériel organique probablement d'origine algale (microphytes ou macrophytes). Dans le sédiment récepteur situé sous les huîtres, l'accroissement du rapport $\mathrm{NH}_{4}$ échangeable sur $\mathrm{NH}_{4}$ dissous des eaux interstitielles est net en mars, juillet et novembre. Le pool d'ammonium échangeable est fort par rapport à l'ammonium dissous, et ce particulièrement en juillet. A cette période, la diminution importante de l'ammonium $13.5 \mathrm{mmol} . \mathrm{m}^{-3}$ de l'eau interstitielle est accompagnée d'un pool d'ammonium échangeable élevé : $0,513 \mu \mathrm{mol} . \mathrm{g} \mathrm{sec}^{-1}$. Ceci indique qu'après le bloom du mois de mai le phytoplancton a pu être dégradé, concentré par les biodépôts des huîtres à la surface du sédiment des zones d'élevage. Ces résultats, minéralisation en début d'été de l'azote organique phytoplanctonique, concordent avec ceux de Blackburn et Henriksen (1983).

Le rapport $\mathrm{NH}_{4}$ échangeable sur $\mathrm{NH}_{4}$ dissous des eaux interstitielles indique la force avec laquelle l'ammonium est retenu dans le pool échangeable, la capacité d'échange restant importante. Le pouvoir d'adsorption élevé représenté par $\mathrm{K}^{*}$ se manifeste au moment où la concentration en matière organique est elle-même élevée, $11.10^{-5} \mathrm{~g} . \mathrm{g} \mathrm{sec}^{-1}$ en juillet (Sornin, 1981). Nous savons que la présence des biodépôts augmente la concentration en matière organique. Ces résultats correspondent à ceux de Rosenfeld (1979) et Mackin et Allen (1984). En été, dans la zone d'élevage, la valeur de $\mathrm{K}^{*}$ et celle des flux sont inversement reliées montrant que la forte adsorption de l'ammonium sur le sédiment s'oppose à un flux faiblement positif.

\section{Relation eau huître sédiment}

Pour reconstituer le cycle de l'azote dans un écosystème conchylicole, il est intéressant de mettre en relation les différents compartiments eau, benthos, interface et sédiment ( fig. 9). Le sédiment et le benthos intègrent d'une manière statique les variations de la colonne d'eau, ainsi le stock d'azote disponible pour le benthos et pour le sédiment est fonction de la concentration d'azote, de la hauteur d'eau, de la vitesse du courant et du temps d'immersion. Pour chaque quinzaine de mortes-eaux et de vives-eaux, la formule suivante est appliquée :

$$
\mathrm{S}=\mathrm{Q} \cdot \mathrm{c} . \mathrm{T}
$$

où

$\mathrm{S}$ : stock d'azote $\left(\mathrm{g} \cdot \mathrm{m}^{-2} \cdot \mathrm{an}^{-1}\right)$ pour la colonne d'eau;

$\mathrm{Q}$ : quantité d'azote en gramme, d'une surface de $1 \mathrm{~m}^{2}$, pour la colonne d'eau;

$c:$ courant moyen $\left(\mathrm{m} . \mathrm{h}^{-1}\right)$;

$\mathrm{T}$ : temps d'immersion annuel en heure.

Le bilan annuel est la somme des 24 calculs de mortes-eaux et vives-eaux. Ce calcul est appliqué (Héral et al., 1983) pour les substances dissoutes aux flux d'azote organique total dissous ainsi qu'au flux d'azote minéral représenté par la somme des concentrations de l'ammonium, des nitrites et nitrates. Ce calcul théorique ne prend pas en compte la circulation des masses d'eau et leur temps de résidence. Une approche utilisant un modèle physique numérique permettrait d'intégrer l'échelle spatiale (Bacher, 1987).

Le flux annuel d'azote minéral dissous est de $10,5 \cdot 10^{6} \mathrm{~g} \cdot \mathrm{m}^{-2}$ tandis que celui de l'azote organique dissous est de $5,6 \cdot 10^{6} \mathrm{~g} . \mathrm{m}^{-2}$ par an. Ainsi l'azote organique dissous représente $50 \%$ des apports d'azote minéral ce qui confirme l'importance de ces composés en zone néritique pour la production primaire (Robert et al., 1982). Le flux d'azote particulaire phytoplanctonique est calculé de manière identique, à partir de l'estimation de la biomasse phytoplanctonique mesurée par les teneurs en chlorophylle $a$ et ses phéopigments, en tenant compte du rapport moyen $\mathrm{C} / \mathrm{N}$ de Redfield $(6,6)$ pour les populations phytoplanctoniques ainsi que de la conversion carbone organique phytoplanctonique $=60$ (chlorophylle + phéopigments) (Strickland, 1960). Ainsi le flux d'azote particulaire d'origine phytoplanctonique de la colonne d'eau est égal à $1,7 \cdot 10^{6} \mathrm{~g} \cdot \mathrm{m}^{-2}$. an ${ }^{-1}$ alors que l'azote organique total particulaire représente $15.10^{6} \mathrm{~g} . \mathrm{m}^{-2}$. an ${ }^{-1}$. L'azote phytoplanctonique ne représente dans ce milieu estuarien que $6 \%$ de l'azote organique particulaire total. Ceci confirme les résultats de Héral et al. (1981, 1983) démontrant que dans cet écosystème, une grande proportion de la matière organique particulaire est d'origine détritique mais peut être utilisée par la chaîne alimentaire avec des rendements énergétiques moindre en particulier pour les mollusques lamellibranches (Stuart et al., 1982; Newell, 1982; Lucas et Newell et al., 1984). 


\section{COLONNE D'EAU}
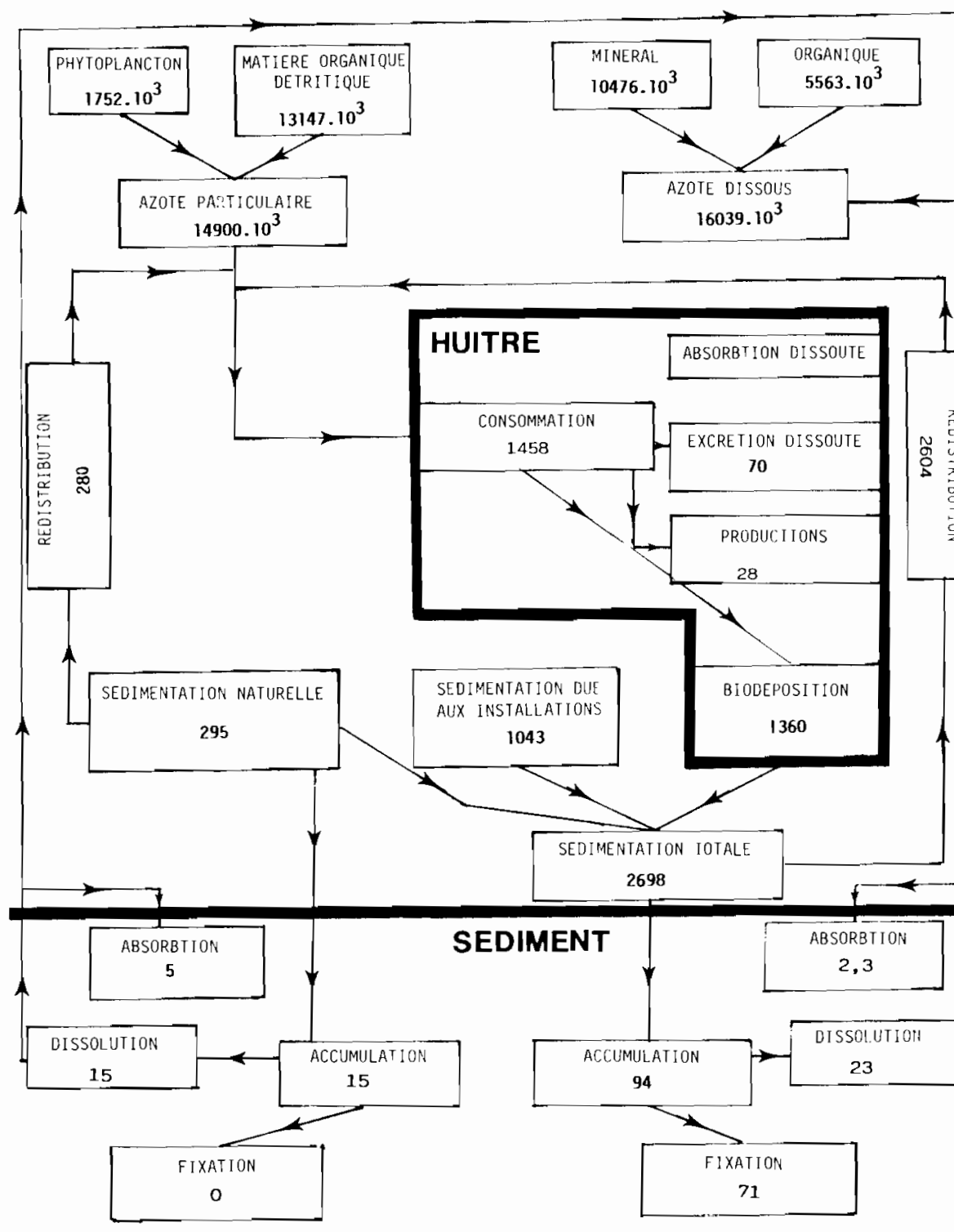
Lcs mesures effectuées sur les échantillons recueillis dans les différcnts pièges et sur le sédiment permettent d'établir des bilans de flux d'azote. Ainsi la sédimentation due aux installations de cultures $\left(1043 \mathrm{~g} \cdot \mathrm{m}^{-2}\right.$ par an) représente à elle seule près de $40 \%$ du total de la sédimentation tandis que la sédimentation naturelle n'est que de $295 \mathrm{~g} . \mathrm{m}^{-2}$ par an. Par des mesures précises de relevés topographiques, les taux de sédimentation ont été estimés à $5 \mathrm{~cm}$ par an sous les cultures d'huîtres et à $1 \mathrm{~cm}$ hors des cultures (Sornin, 1981). Avec la densité, la teneur en eau, la concentration en azote, les quantités accumulées annuelles sont calculées. Ainsi dans les zones de cultures d'huîtres, l'accumulation d'azote est de $94 \mathrm{~g} \cdot \mathrm{m}^{-2}$ par an, alors que sur la vasière témoin elle est de $15 \mathrm{~g} . \mathrm{m}^{-2}$ par an. La redistribution due à la remise en suspension représente donc $95 \%$ sur un sol non cultivé. Les modifications hydrodynamiques induites par les structures d'élevage ainsi que les changements de nature de la sédimentation (biodéposition, mucus) provoquent une accumulation azotée accrue dans les zones de culture. Le flux de composés azotés minéraux dissous (ammonium et nitrates) issus du sédiment vers la colonne d'eau est plus élevé sous les cultures (23 g. $\mathrm{m}^{-2}$ par an) que sur le sédiment témoin (15 g. $\mathrm{m}^{-2}$ par an). Par contre le flux inverse, absorption d'azote du sédiment en provenance de la colonne d'eau est faible pour la zone à huîtres $\left(2,3 \mathrm{~g} \cdot \mathrm{m}^{2}\right.$ par an) alors qu'elle est de $4,9 \mathrm{~g} \cdot \mathrm{m}^{-2}$ par an pour la zone témoin semblant indiquer une saturation du sédiment sous les huîtres. L'accumulation. d'azote dans le sédiment sous les huîtres est de $71 \mathrm{~g} \cdot \mathrm{m}^{-2}$. an ${ }^{-1}$. Dans la zone témoin, on constate un équilibre entre l'accumulation et les flux en provenance du sédiment vers la colonne d'eau. Ainsi, la présence de cultures d'huîtres induit annuellement un apport supplémentaire d'azote de $71 \mathrm{~g} \cdot \mathrm{m}^{-2}$. Ce résultat est à mettre en relation avec l'accumulation de phosphore $\left(23 \mathrm{~g} \cdot \mathrm{m}^{-2}\right.$ par an, constaté sur ce même parc d'élevage (Sornin et al., 1986). Ce bilan annuel masque cependant deux comportements saisonniers différents :

- en hiver, forts apports d'azote minéral dans la colonne d'eau, absorption par les sédiments de nitrates, forte production de biodépôts dont la teneur en azote est pauvre;

- au printemps et à l'automne, peu d'apport d'azote minéral dans la colonne d'eau, abondance d'azote organique en relation avec l'excrétion des mollusques, relargage par le sédiment d'ammonium et de nitrate lié à une minéralisation rapide des biodépôts riches en azote.

Ce bilan reste néanmoins incomplet, il ne prend pas en compte la production primaire et en particulier la production phytobenthique qui utilise l'azote et le phosphore accumulé dans le sédiment. De plus, ce bilan ne tient pas compte de la microfaune et macrofaune benthique autre que les huîtres qui peuvent augmenter les flux d'azote comme Boucher et al. (1985) l'ont mis en évidence.

Ce travail expérimental montre que si les cultures d'huîtres sont réalisées toute l'année sur le même terrain, il se produit une accumulation certaine d'azote sur le sédiment. Cependant, il faut préciser que cet état de fait ne correspond pas à la technique ostréicole pratiquée dans le bassin de MarennesOléron où se réalise une jachère hivernale. Elle évite ainsi une sédimentation cumulée en favorisant une remise en suspension du sédiment par le fort hydrodynamisme lié aux tempêtes d'hiver.

\section{Remerciement}

Les auteurs remercient R. Chevalier pour l'ensemble des tests statistiques utilisés dans ce travail, ainsi que D. H. T. Blackburn, pour l'attention qu'il a apportée à cette étude et les conseils qu'il a prodigués pour l'élaboration de ce manuscrit. Les auteurs tiennent à remercier un referry dont les remarques ont été très constructives.

\section{RÉFÉRENCES}

Aminot A., R. Kerouel, 1982. Dosage automatique de l'urée dans l'eau de mer : une méthode très sensible à la diacetylmonoxime. Can. J. Fish. Aquat. Sci., 39, 174-183.

Armstrong F. A. J., S. Tibbits, 1968. Photochemical combustion of organic matter in sea water for nitrogen, phosphorus and carbon determination, J. Mar. Biol. Assoc. U. K., 48, 143-152.
Bacher C., 1987. Modélisation de la croissance des huitres dans le bassin de Marennes-Oléron. Rapp. IFREMERMER, 86-50051, 12 p.

Billen G., 1976. Étude écologique des transformations de l'azote dans les sédiments marins. Thèse, Univ. Libre, Bruxelles, 266 p.

-, 1978. A budget of nitrogen recycling in North Sea sediments off the Belgian coast. Estuar. Coast. Mar. Sci., 7, 127-146.

Billen G., J. P. Vanderborght, 1978. Evaluation of the exchange fluxes of material between sediments and overlying waters from direct measurements of bacterial 
activity and mathematical analysis of vertical concentration profiles in interstitial waters in Biogeochemistry of estuarine sediments. Proceedings of UNESCO/SCOR, workshop. UNESCO, Paris, 115-165.

Blackburn T. H., K. Henriken, 1983. Nitrogen cycling in different types of sediments from Danish waters. Limmol. Oceanogr., 28, 477-493.

Boucher G., R. Boucher-Rodoni, 1985. Métabolisme respiratoire et échanges azotés à l'interface des parcs ostréicoles. Rapp. CNRS/CNEXO 84/3082, 51 p.

Christensen J. P., G. T. Rowe, C. H. Clifford, 1983. The possible importance of primary amino nitrogen regeneration by coastal marine sediments in Buzzards Bay, Massachussetts, Int. Rev. Ges. Hydro-biol., 68, 501-512.

Deslous-Paoli J. M., M. Héral, 1988. Proximate biochemical composition and energy value of Crassostrea gigas (Thunberg) cultured in the bay of Marennes-Oléron. Aquat. Living Resour., 1.

Deslous-Paoli J. M., M. Héral, P. Goulletquer, W. Boromthanarat, D. Razet, J. Garnier, J. Prou, L. Barillet, 1987. Évolution saisonnière de la filtration de bivalves intertidaux dans des conditions naturelles. Journées du GABIM, nov. 1986, L'Houmeau. Océanis, 13, 575-579.

Deslous-Paoli J. M., J. M. Sornin, M. Héral, 1987. Biodéposition et digestibilité des aliments in situ pour trois mollusques estuariens (Mytilus edulis, Crassostrea gigas, Crepidula fornicata). Haliotis, 16, 233-245.

Drouineau G., P. Gouny, 1947. Contribution à l'étude du dosage de l'azote nitrique par la méthode Dewarda. Ann. Agr., 2.

Feuillet M., 1971. Relations entre les eaux interstitielles des fonds sédimentaires ostréicoles et le milieu hydrobiologique. Le bassin des Chasses des Sables d'Olonne. Rev. Trav. Inst. Pêches marit., 35, 435-442.

Feuillet M., 1980. Contribution à l'étude des fonds ostréicoles du marais des Loirs au nord des Sables-d'Olonne. Bull. Soc. Géol. Normandie Amis. Mus-Havre, 67, 43-61.

Feuillet M., D. Gouleau, 1977. Action des épandages de craie $\left(\mathrm{CaCO}_{3}\right)$ sur les vases des claires et des parcs ostréicoles. Rev. Trav. Inst. Pêches marit., 41, 417-436.

Flamion G., 1983. Accroissement de la production phytoplanctonique par des amendements minéraux dans une nurserie de mollusques. Mémoire DEA, Univ. Rennes, $32 \mathrm{p}$.

Giese A. C., 1969. A new approach to the biochemical composition of the mollusc body. Oceanogr. Mar. Biol. Ann. Rev., 7, 175-229.

Henrichs S. M., J. W. Farrington, 1979. Amino acids in interstitial water of marine sediments. Nature, 279, 319322.

Héral M., 1985. L'ostréiculture française traditionnelle. Aquaculture éd. Lavoisier, Paris, 346-390.

Héral M., J. M. Deslous-Paoli, P. Goulletquer, D. Razet, J. Prou, B. Ravail, M. L. Vincendeau, 1987. Variations saisonnières de l'excrétion azotée et de la respiration de cinq mollusques intertidaux : l'huître (Crassostrea gigas), la moule (Mytilus edulis), la coque (Cerastoderma edule), la palourde japonaise (Ruditapes philippinarum) et la crépidule (Crepidula fornicata). Haliotis (sous presse).

Héral M., J. M. Deslous-Paoli, J. M. Sornin, 1983 a. Transferts énergétiques entre l'huître Crassostrea gigas et la nourriture potentielle disponible dans un bassin ostréicole : premières approches. Océanis, 9, 169-194.

Héral M., Razet D., Deslous-Paoli J. M., Berthomé J. P., Garnier J., $1983 b$, Caractéristiques saisonnières de l'hydrobiologie du complexe estuarien de Marennes-Oléron (France). Rev. Trav. Inst. Pêches marit., 46, 97-119.

Héral M., Razet D., Deslous-Paoli J. M., Manaud F., Truquet I., Garnier J., 1984. Hydrobiologe du bassin de Marennes-Oléron : résultats du réseau national d'observation : 1977 à 1981. Ann. Soc. Sci. Nat. Charente-Maritime, 7, 259-277.

Héral M., D. Razet, S. Maestrini, J. Garnier, 1980. Composition de la matière organique particulaire dans les eaux du bassin de Marennes-Oléron. Apport énergétique pour la nutrition de l'huître. Cons. Int. Explor. Mer, C. $\mathbf{M} / 1980: \mathrm{L} 44,14 \mathrm{p}$.

Héral M., J. M. Robert, J. Truquet, O. Barbaroux, J. Garnier, D. Razel, 1981. Composition en éléments azotés minéraux et organiques dissous de l'eau du bassin conchylicole de Marennes-Oléron. Cons. Int. Explor. Mer, C.M./1981 : E 58, 9 p.

Ito S., T. Imaî, 1955. Ecology of oyster bed on the decline of productivity due to repeated cultures. Tohoku J. Agric. Res., 4, 251-268.

J $\phi$ rgensen N. O. G., 1979. Annual variation of dissolved free primary amines in estuarine water and sediment. Oecologia, 40, 207-217.

J $\phi$ rgensen N. O. G., P. Lindroth, K. Mopper, 1981. Extraction and distribution of free amino acids and ammonium in sediment interstitial waters from the Limfjord Denmark. Oceanol. Acta, 4, 465-474.

Kerambrun P., K. H. Szekielda, 1969. Dosage simultané du carbone de l'hydrogène et de l'azote dans le matériel en suspension dans l'eau de mer, note tech. Téthys, 1, 581-584.

Koroleff F., 1970. Direct determination of ammonia in natural waters as indophenol blue (revised). Information on technique and methods for sea-water analysis interlab. Rep. Cons. int. Explor. Mer, 3, 19-22.

Krom M. D., R. A. Berner, 1980. The diffusion coefficients of sulfate, ammonium and phosphate in anoxic marine sediments. Limnol. Oceanogr., 25, 327-337.

Kusuki Y., 1981. Fundamental studies on the deterioration of oyster growing grounds. Bull. Iroshima Fish., Experiment. St, 11, 93 p.

Laborde P., 1984. L'azote inorganique interstitiel des sédiments de quelques marges continentales. Relations avec le matériel organique fixé, la biomasse et les modalités de la sédimentation. Thèse dr. État, Univ. Marseille, $168 \mathrm{p}$.

Lerat Y., G. Boucher, P. Le Corre, 1985. Échanges à l'interface eau-sédiment dans un secteur côtier à forte biodéposition (parc ostréicole), cas de l'ammonium et des nitrates. Cah. Biol. Mar., 26, 393-408.

Liu K. K., L. S. Fang, 1986. Nutrient cycling in the Penghu Bay : a study on nutrient regeneration in sediments in an oyster farm. Acta Oceanogr. Taiwanica, 17, 45-60.

Lowry O. H., N. I. Roseborough, A. L. Farrand, R. J. Randall, 1951. Protein measurement with the folin phenol reagent. J. Biol. Chem., 193, 263-275. 
Lucas M. I., R. C. Newell, 1984. Utilisation of saltmarsh grass detritus by two estuarine bivalves: carbohydrase activity of crystalline style enzymes of the oyster Crassostrea virginica and the mussel Geukensia demissa. Mar. Biol. Letters, 5, 275-290.

Malara G., R. Chara, 1972. Dosage des protéines particulaires selon la méthode de Lowry et dosage des glucides particulaires du phytoplancton selon la méthode de Dubois. Note S. Z. V. Villefranche-sur-mer, 5 et 6.

Mackin J. E., R. C. Aller, 1984. Ammonium adsorption in marine sediments. Limnol. Oceanogr., 29, 250-257.

Newell R. C., J. G. Field, C. L. Griffiths, 1982. Energy balance and the significance of micro-organisms in a kelp bed comunity. Mar. Ecol. Prog. Ser., 5, 356-369.

North, 1975. Primary amines in California coastal waters: Utilization by phytoplankton. Limnol. Oceanogr., 20, 2027.

Pomroy A. J., I. R. Joint, K. R. Clarke, 1983. Benthic nutrient flux in a shallow coastal environment. Oecologia, 60, 306-312.

Robert J. M., 1982. Fertilité des eaux des claires ostréicoles et verdissement : utilisation de l'azote par les diatomées dominantes. Thèse dr. Etat, Univ. Nantes, 281 p.

Robert J. M., S. Y. Maestrini, M. Héral, Y. Rince, J. P. Dreno, Z. Beker, $1982 a$. Enrichissement expérimental d'eaux printanières de claires à huîtres en baie de Bourgneuf (Vendée, France) : augmentation de la biomasse et utilisation des éléments nutritifs par les algues unicellulaires. Hydrobiol., 95, 53-63.

Robert J. M., S. Y. Maestrini, M. Héral, Y. Zanette, 1982 b. Production de micro-algues des claires ostréicoles en relation avec l'azote organique dissous excrété par les huitres Oceanol. Acta, Actes Symposium International sur les lagunes côtières, Scor/IABO, UNESCO, Bordeaux, 389-395.

Rosenfeld J. K., 1979. Ammonium adsorption in nearshore anoxic sediments. Limnol. Oceanogr., 24, 356-364.
Rowe G. T., C. H. Clifford, J. R. K. L. Smith, 1975. Nutrient regeneration in sediments of Cape Blanc, Spanish Sahara. Deep Sea Res., 24, 53-54.

Rutgers van der Loeff M. M., 1980. Nutrients in the interstitial waters of the southern bight of the North Sea. Neth. J. Sea Res., 14, 144-171.

Rutgers van der Loeff M. M., F. B. van Es, W. Helder, R. T. P. De Vries, 1981. Sediment water exchanges of nutrients and oxygen on tidal flats in the Ems Dollard estuary. Neth. J. Sea Res., 15, 113-129.

Simon N. S., 1988. Nitrogen cycling between sediment and the shallow-water column in the transition zone of the Potomac River and Estuary. I. Nitrate and Ammonium Fluxes. Estuar. Coast. Shelf Sci., 26, 483-497.

Sornin J. M., 1981. Processus sédimentaires et biodéposition liés à différents modes de conchyliculture. Thèse $3^{\text {e }}$ cycle, Univ. Nantes, $1984 \mathrm{p}$.

Sornin J. M., M. Feuillet, M. Héral, J. M. Deslous-Paoli, 1983. Effets des biodépôts de l'huittre Crassostrea gigas (Thunberg) sur l'accumulation de matières organiques dans les parcs du bassin de Marennes-Oléron. J. Moll. Stud., 12A, 185-197.

Sornin J. M., M. Feuillet, M. Héral, J. C. Fardeau, 1986. Influence des cultures d'huîtres Crassostrea gigas sur le cycle du phosphore en zone intertidale : rôle de la biodéposition. Océanol. Acta, 9, 313-322.

Strickland J. D. H., 1960. Measuring the production of marine phytoplankton. Bull. Fish. Res. Board Can., 122, 1-172.

Strickland J. D. H., T. R. Parsons, 1972. A practical Handbook of sea water analysis. Bull. Fish. Res. Board Can., 167, $310 \mathrm{p}$.

Stuart V., J. G. Field, R. C. Newell, 1982. Evidence for absorption of kelp detritus by the ribbed mussel Aulacomya ater using a new $57 \mathrm{Cr}$-Labelled microsphere technique. Mar. Ecol. Prog. Ser., 9, 265-271.

Vincendeau M. L., 1987. Étude expérimentale de la fertilité des eaux des milieux conchylicoles : influence de l'excrétion des huîtres et des palourdes sur la production des diatomées dominantes. Thèse dr., Univ. Paris-VI, $156 \mathrm{p}$. 